\title{
Improving the reproductive function of replacement and adult sows
}

\author{
G.S. Pokhodnya ${ }^{1}$, A.V. Kosov ${ }^{1}$, V.M. Breslavets, ${ }^{1, *}$ Yu.P. Breslavets, ${ }^{1}$ and N.V. \\ Perevozchikov ${ }^{1}$ \\ ${ }^{1}$ Belgorod State Agrarian University named after V.Ya. Gorin, 1 Vavilova Str., Maysky village, \\ Belgorodsky district, 308503 Belgorod region, Russian Federation
}

\begin{abstract}
Studies have shown that feeding the feed additive "Elevit" during the preparation of sows for insemination in a dosage of $1.0 ; 2.0 ; 3.0 ; 4.0 \%$ over the basic daily diet can increase estrum in replacement sows by 6.6 ; $20.0 ; 26.6 ; 26.6 \%$, respectively, fertilization and prolificacy by $2.1 ; 5.3 ; 6.6$; $6.6 \%$ and $1.0 ; 4.3 ; 7.6 ; 6.5 \%$, respectively. Such a significant increase in the previously mentioned indicators also led to an increase in the total number of piglets by $13.5 ; 43.2 ; 60.8 ; 59.4 \%$, respectively, while their cost at birth decreased by $11.5 ; 29.7 ; 37.4 ; 36.7 \%$ compared to the control group. Similar results were obtained from adult sows - estrum increased by $3.4 ; 10.0 ; 10.0$; $10.0 \%$, fertilization and prolificacy by $0.5 ; 5.0 ; 5.0 ; 5.0 \%$ by $0.9 ; 8.2 ; 8.2$; $9.1 \%$, respectively. At the same time, the total number of piglets at birth increased by $5.8 ; 28.7 ; 28.3 ; 29.1 \%$. Their cost at birth decreased in comparison with the first control group by $5.2 ; 21.9 ; 21.5 ; 21.8 \%$. From the data obtained by us, the best option for feed additive "Elevit" feeding both in terms of zootechnical and economic efficiency is - for replacement gilts in the amount of $3.0 \%$; for adult sows $-2.0 \%$ over the basic daily diet for the period of preparation for insemination.
\end{abstract}

\section{Introduction}

The experience and practice of industrial pig breeding accumulated over the past 50 years in our country have shown that at present, in the conditions of industrial technology, not all animals show high productivity, despite their high genetic potential $[1,2,3,4,5,12,14,16,18]$. Considering that it is practically problematic to change the industrial technology of pork production, scientists and specialists are trying to somehow reduce the negative impact of this technology by improving their feeding $[7,8,9,11,12,13,15,17]$.

The main direction of increasing the usefulness of pig diets is the use of various biologically active drugs and feed additives [6,10,19,20].

So, in the Belgorod region, the company "VITA" LLC has developed a new feed additive called "Elevit". This feed additive was obtained as a result of special treatment of the wheat grain germ part.

The qualitative characteristics of the feed additive "Elevit", including the features of the chemical composition, showed the following: in terms of its indicators, this feed additive is

\footnotetext{
*Corresponding author: umat_05@mail.ru
} 
in no way inferior to traditional animal feeds, such as chicken eggs, cow's milk, fish flour, etc., and in many ways exceeds them [3.13].

When developing the technology for the production of the feed additive "Elevit", it was found that at high pressure, the wheat germ is deformed and the protective coating is destroyed. Therefore, when the feed additive "Elevit" enters the stomach of pigs, the assimilation of nutrients begins immediately. It should also be noted that the feed additive "Elevit" is rich in vitamins, essential amino acids, micro- and macronutrients and other important components for the animal body $[8,13]$. However, despite the excellent characteristics (in terms of chemical composition) of the feed additive "Elevit", it is necessary to confirm its value by the effectiveness of its use in animal diets. This is what our scientific work is devoted to, the results of which are given in this article.

\section{Materials and methods of research}

To study the effectiveness of using the feed additive "Elevit" in the diets of replacement gilts and adult sows during the preparation for insemination, a number of special experiments were carried out on the basis of the APC "Collective Farm n.a. Gorin" of the Belgorod region.

The first experiment was based on the classical model: five groups of 8-month-old replacement gilts were selected based on the principle of analogues. Each group consisted of 30 gilts. Further, when transferring to the reproduction shop, all groups of gilts were kept in the same conditions, while they were fed differently: the control group of gilts was fed with the main diet, which was compiled according to the standards of the All-Russian Institute of Livestock Breeding, and the experimental groups $(2,3,4,5)$ received the feed additive "Elevit" in the dosage of $1.0 ; 2.0 ; 3.0 ; 4.0 \%$, respectively, to the groups.

Thus, the feeding with the feed additive was carried out before estrum manifestation in them, but it did not exceed more than 20 days or one estrum cycle. Further, sows were sampled in the estrum, which was carried out in the morning and evening using a probe boar during the estrum cycle.

Gilts that showed estrum on the second day were transferred to the artificial insemination point. There was carried out 2-fold insemination of gilts - at the time of their selection and exactly one day later.

The second experiment was carried out by analogy with the first one, with the only difference that 5 groups of adult sows aged 2.5-3 years were selected according to the principle of analogues. Each group included 30 sows after weaning their piglets on 28 day. Then the second experiment was conducted fully in accordance with the previously described method of the first experiment.

\section{Results of the study and their discussion}

At the beginning of the first experiment, we studied the estrum manifestation in replacement gilts depending on feeding them with the feed additive "Elevit" during their preparation for insemination

Effect of the feed additive "Elevit" on the estrum manifestation in replacement gilts is shown in Fig. 1. 


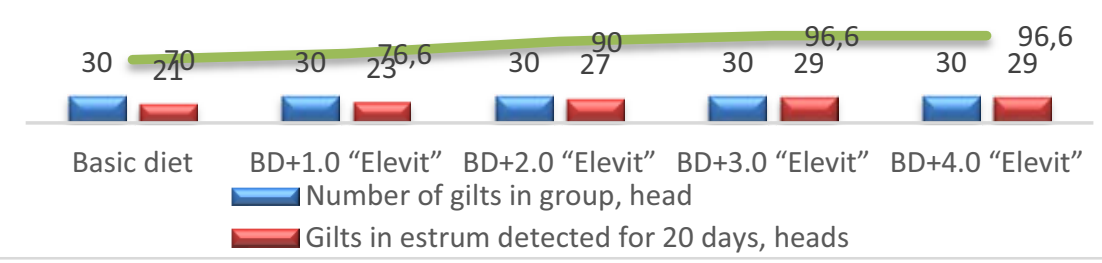

Fig. 1. Estrum manifestation in replacement gilts depending on feeding them with the feed additive "Elevit"

So, Fig. 1 clearly shows that the introduction of the feed additive "Elevit" into the diet of replacement gilts tested by us in a dosage of $1.0 ; 2.0 ; 3.0 ; 4.0 \%$ in addition to the daily diet has a positive effect on the estrum manifestation in gilts. This indicator increased significantly - by $6.6 ; 20.0 ; 26.6 ; 26.6 \%$, respectively, when compared with the first control group.

Here we should highlight the indicators that were obtained in the fourth and fifth experimental groups. After all, it is not so easy to increase the number of inseminated sows on any pig farm or pig breeding complex by $26.6 \%$, and if this is achieved in our case, this is a huge reserve for increasing pork production and significantly reducing the cost of its production.

However, it should be remembered that increasing the number of inseminated gilts is not a complete success, it is necessary that these gilts are fertilized, and they need to get as many offspring as possible.

Effect of the feeding of replacement gilts with the feed additive "Elevit" on the receipt of piglets from them is given in data in table 1 .

Table 1. Effectiveness of artificial insemination of replacement gilts depending on feeding them with the feed additive "Elevit"

\begin{tabular}{|c|c|c|c|c|c|c|c|}
\hline $\begin{array}{l}\text { Experimental } \\
\text { groups }\end{array}$ & $\begin{array}{c}\text { Amount of } \\
\text { feed additive } \\
\text { in gilt diet, \% }\end{array}$ & \multicolumn{3}{|c|}{ Number of sows } & \multicolumn{2}{|c|}{$\begin{array}{c}\text { Piglets received, } \\
\text { head }\end{array}$} & $\begin{array}{c}\text { Average live } \\
\text { weight of 1 } \\
\text { piglet at birth, kg }\end{array}$ \\
\cline { 3 - 7 } & & $\begin{array}{c}\text { Inseminated, } \\
\text { head }\end{array}$ & $\begin{array}{c}\text { Farrowed, } \\
\text { head }\end{array}$ & $\begin{array}{c}\text { Fertilization, } \\
\%\end{array}$ & total & $\begin{array}{c}\text { Per 1 } \\
\text { farrow }\end{array}$ & \\
\hline 1 & 0 & 21 & 16 & 76.1 & 148 & $9.2 \pm 0.10$ & $1.26 \pm 0.02$ \\
\hline 2 & 1.0 & 23 & 18 & 78.2 & 168 & $9.3 \pm 0.10$ & $1.25 \pm 0.01$ \\
\hline 3 & 2.0 & 27 & 22 & 81.4 & 212 & $9.6 \pm 0.10$ & $1.25 \pm 0.01$ \\
\hline 4 & 3.0 & 29 & 24 & 82.7 & 238 & $9.9 \pm 0.08$ & $1.24 \pm 0.03$ \\
\hline 5 & 4.0 & 29 & 24 & 82.7 & 236 & $9.8 \pm 0.10$ & $1.24 \pm 0.02$ \\
\hline
\end{tabular}

Our assumptions turned out to be correct - the introduction of the feed additive "Elevit" into the diet of replacement gilts during preparation for insemination has a positive effect not only on estrum increase - the number of piglets received for 1 farrowing also increases.

The data shown in table 1 tell us that the increase in the number of piglets received was due to an increase in fertilization and prolificacy in replacement gilts. In the replacement gilts we tested, fertilization increased by $2.1 ; 5.3 ; 6.6 ; 6.6 \%$, respectively, while prolificacy increased by $1.0 ; 4.3 ; 7.6 ; 7.6 \%$, respectively. The growth of these indicators led to an increase in the number of piglets received by $13.5 ; 43.2 ; 60.8 ; 59.4 \%$, respectively, in the experimental groups in comparison with the control group.

The last data shown in table 1 confirm the importance of estrum manifestation in replacement gilts in one estrum cycle or 20 days after their transfer to the reproduction shop, as we noted earlier. 
And yet, no matter how high the sow productivity indicators are in the studies, they need to be confirmed by economic efficiency. We did this by analyzing the cost-effectiveness of using the "Elevit" feed additive in the diets of replacement gilts during their preparation for insemination. Our calculations showed that our experiment had a positive impact on the cost of 1 piglet (Fig.2).

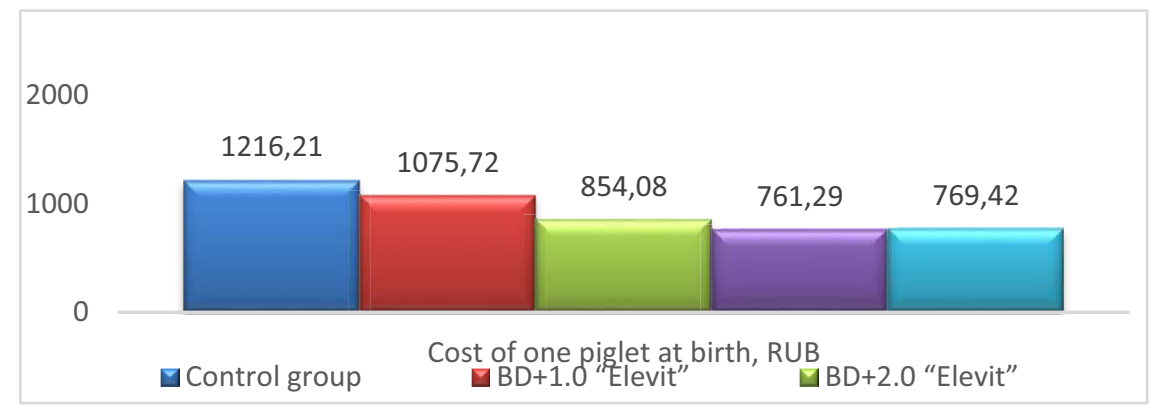

Fig. 2. Cost of 1 piglet at birth, which were obtained from replacement gilts that received the feed additive "Elevit" during their preparation for insemination

Summarizing the data obtained by us and analyzing them, it is important to note the following: by introducing the feed additive "Elevit" in the diet of replacement gilts, the indicators of fertilization and prolificacy increased, which thereby led to an increase in the number of piglets received at birth in the experimental groups. This fact explains the decrease in their cost by $11.5 ; 29.7 ; 37.4 ; 36.7 \%$, respectively, compared with the first control group.

It is known that with the estrum manifestation, in the conditions of industrial technology, there is a problem in adult sows. Given this, in the second similar experiment, we studied the question - how does feeding of the feed additive "Elevit" to adult sows affect their reproductive function? This supplement was fed to adult sows after weaning the piglets at the age of 28 days and transferring the sows to the reproduction shop for 20 days.

Depending on the feeding of the feed additive "Elevit", estrum in adult sows manifested in different ways, as evidenced by the data shown in Fig. 3.

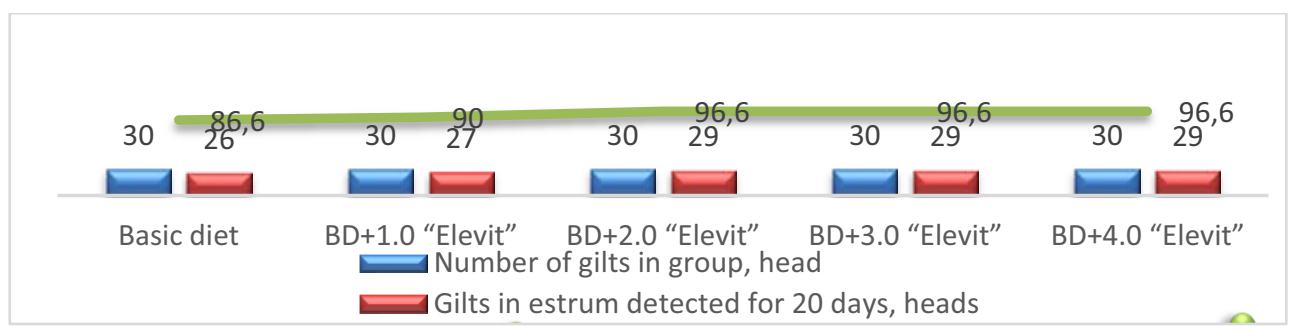

Fig. 3. Effect of feeding of the feed additive "Elevit" to adult sows on estrum manifestation

As we expected, the introduction of the feed additive "Elevit" into the diet of adult sows during their preparation for insemination had a positive effect on the sexual function of sows.

Of course, this effect in adult sows was slightly lower than in replacement gilts. And it was noted in an increase in estrum manifestation in adult sows of the experimental groups (groups $2-5$ ) by $3.4 ; 10.0 ; 10.0 ; 10.0 \%$, respectively, compared with the first control group.

The effect of feeding adult sows with the feed additive "Elevit" on the effectiveness of their insemination can be traced based on the data in table 2 .

Table 2. Effect of feeding of the feed additive "Elevit" to adult sows on the effectiveness of their insemination 


\begin{tabular}{|c|c|c|c|c|c|c|c|}
\hline \multirow{2}{*}{\begin{tabular}{l}
$\dot{0}$ \\
$z$ \\
\hdashline \\
0 \\
0
\end{tabular}} & \multirow{2}{*}{$\begin{array}{c}\text { Feeding } \\
\text { conditions for } \\
\text { adult sows }\end{array}$} & \multicolumn{3}{|c|}{ Number of sows } & \multicolumn{2}{|c|}{$\begin{array}{c}\text { Piglets received, } \\
\text { head }\end{array}$} & \multirow{2}{*}{$\begin{array}{l}\text { Average live } \\
\text { weight of } 1 \\
\text { piglet at } \\
\text { birth, kg }\end{array}$} \\
\hline & & $\begin{array}{c}\text { Inseminated, } \\
\text { head }\end{array}$ & $\begin{array}{c}\text { Farrowed, } \\
\text { head }\end{array}$ & Fertilization, \% & total & $\begin{array}{l}\text { Per } 1 \\
\text { farrow }\end{array}$ & \\
\hline 1 & Basic diet & 26 & 22 & 84.6 & 240 & $10.9 \pm 0.1$ & $1.28 \pm 0.02$ \\
\hline 2 & $\begin{array}{c}\text { BD+1.0\% } \\
\text { "Elevit" }\end{array}$ & 27 & 23 & 85.1 & 254 & $11.0 \pm 0.1$ & $1.28 \pm 0.03$ \\
\hline 3 & $\begin{array}{l}\text { BD+2.0\% } \\
\text { "Elevit" }\end{array}$ & 29 & 26 & 89.6 & 309 & $11.8 \pm 0.1$ & $1.27 \pm 0.02$ \\
\hline 4 & $\begin{array}{l}\text { BD+3.0\% } \\
\text { "Elevit" }\end{array}$ & 29 & 26 & 89.6 & 308 & $11.8 \pm 0.1$ & $1.27 \pm 0.01$ \\
\hline 5 & $\begin{array}{l}\text { BD+4.0\% } \\
\text { "Elevit" }\end{array}$ & 29 & 26 & 89.6 & 310 & $11.9 \pm 0.1$ & $1.27 \pm 0.02$ \\
\hline
\end{tabular}

The data shown in table 2, once again convince us of the positive effect of the feed additive "Elevit" when feeding it to adult sows on their reproductive function. In this case this is expressed in an increase of fertilization and prolificacy of sows in the experimental groups, respectively, by $0.5 ; 5.0 ; 5.0 ; 5.0 \%$ and $0.9 ; 8.2 ; 8.2 ; 9.1 \%$, respectively, compared to the first control group. The introduction of the feed additive "Elevit" into the diet of adult sows in the named amount does not affect the live weight of the piglets received. The difference between the experimental groups of sows for this indicator is statistically unreliable. Analyzing table 2 as a whole, it should be noted that according to the main indicator - piglets receipt, there are 3 groups (3-5 groups) - 309; 308; 310 piglets, but this advantage still needs to be proved economically, namely by calculating the cost of one piglet born.

We did this by offering the data in figure 4 .

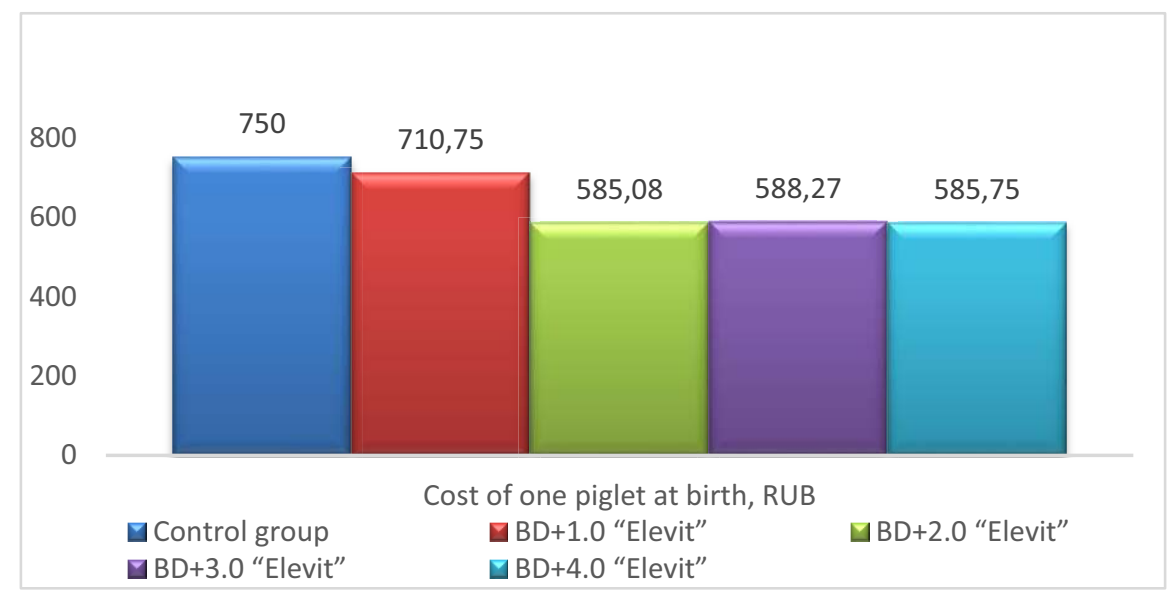

Fig. 4. Cost of 1 piglet at birth, which were obtained from adult sows that received the feed additive "Elevit" during their preparation for insemination

As we can see, the data shown in Fig. 4 allow to conclude that feeding of adult sows during their preparation for insemination with the feed additive "Elevit" is appropriate both for zootechnical and economic indicators.

This is clearly indicated by the data of research results. As we noted earlier, the introduction of the feed additive "Elevit" into the diet of adult sows after weaning their piglets and transferring them to the reproduction shop leads to an increase in estrum, fertilization, and prolificacy in sows. The increase in these indicators, in turn, led to an increase in the number of piglets received at birth in the experimental groups by $5.8 ; 28.7 ; 28.3 ; 29.1 \%$, 
respectively. In addition, we should especially note the reduction in the cost of these piglets at birth, which decreased respectively for the experimental groups in comparison with the control group by $5.2 ; 21.9 ; 21.5 ; 21.8 \%$.

\section{Conclusions}

From all the above, it follows that feeding of the feed additive "Elevit" during the preparation for insemination to replacement gilts and adult sows, both for zootechnical and economic efficiency, is a justified measure.

The presented data allow us to conclude that the most effective in all indicators is considered to be feeding of the feed additive "Elevit" to replacement gilts in the amount of $3.0 \%$, and for adult sows in the amount of $2.0 \%$ in excess of the basic daily diet for a period of 20 days after their transfer to the reproduction shop.

\section{References}

1. S.N. Aleynik, G.S. Pokhodnya, A.N. Dobudko, Reproductive function and productivity of purebred and local Large White and Yorkshire boars (Belgorod: LLC RPC "Polyterra", 2020)

2. A.M. Khokhlov, G.S. Pokhodnya, Agrarian Science, 10, 13-16 (2006)

3. I.F. Gorlov, L.A. Breusova, Bulletin of the Russian Academy of Agricultural Sciences, 1, $31(2013)$

4. N.I. Zhernakova, A.N. Dobudko, T.A. Malakhova et al., Optimization of housing of single sows during their preparation for insemination (Belgorod: Belgorod SAU, 2016)

5. S.N. Aleynik, Achievements of science and technology of the agro-industrial complex, 6, 26-28 (2008)

6. G.S. Pokhodnya, Main breeds of pigs for meat production (Belgorod: Belgorod SAA, 2006)

7. Yu.P. Breslavets, Growth, development and meat qualities of pigs when feeding them with Chlorella suspension (Belgorod: Belgorod SAU, 2015)

8. A.T. Mysik, G.S. Pokhodnya, T.A. Malakhova [et al.], Zootechny, 3, 24-28 (2020)

9. A.G. Narizhny, G.S. Pokhodnya, Pig Breeding, 5, 23 (1995)

10. E.G. Fedorchuk, Zootechny, 5, 8-10 (2014)

11. L.N. Gamko, D.K. Ufimtsev, Forage Production, 2, 45-46 (2011)

12. A.T. Mysik, N.N. Sorokina, N.B. Ordina, V.N. Seleznev, A.V. Sergienko, Zootechny, 12, 14-17 (2019)

13. John. A.Beck, PLOS ONE, 5(5), 10-16 (2018)

14. H. Hammami, B. Rekik, C. Bastin, et all, J. Dairy Sci., 92(9), 4604-4612 (2019)

15. J. Lewis, J. Abas, C. Dadousis, et al., PLOS ONE, (6)4, 18-27 (2015)

16. E. Seroussi, Glick., A. Shirak et al., BMC Genomics, 11, 673-701 (2015)

17. J. Weller, M. Ron, Dairy Sci., 94(3), 1082-1090 (2016)

18. M. Gautier, Denis Laloë, Katayoun Moazami-Goudarzi, PLOS ONE, 5(9), 13-38 (2016)

19. V.P. Zhabinskaya, N.S. Trubchaninova, G.S. Pokhodnya, D.V. Korobov, V.I. Kotarev, O.E. Tat'yanicheva, N.B. Ordina, International of Advanced Biotechnology and Research 10(1), 47-53 (2019) 